\title{
TÁC ĐỘNG CỦA CÁC YẾU TỐ MARKETING ĐỊA PHƯƠNG ĐẾN THU HÚT ĐẦU TỦ TẠI TỈNH ĐĂKK NÔNG
}

\author{
THE IMPACT OF MARKETING PLACE TO ATTRACT \\ INVESTMENT IN THE PROVINCE: EMPIRICAL EVIDENCE \\ FROM DAKNONG
}

\section{Nguyễn Văn Hiến, Ao Thu Hoài ${ }^{1}$}

Ngày nhận bài: 04/11/2019 Ngày chấp nhận đăng: 18/11/2019 Ngày đăng: 05/12/2019

\section{Tóm tắt}

Marketing địa phương đóng vai trò quan trọng để xây dựng hình ảnh địa phương nhằm thu hút các nhà đầu tư, khách du lịch, dân cư và lao động đến với địa phương để thúc đẩy phát triển kinh tế xã hội của địa phương. Nghiên cứu này thực hiện khảo sát 200 nhà đầu tư trong và ngoài tỉnh Đắk Nông để xác định và đo lường 5 yếu tố thuộc marketing địa phương tác động đến thu hút đầu tư vào tỉnh gồm: (1) Cơ sở hạ tầng hỗ trợ doanh nghiệp; (2) Chế độ chính sách và dịch vụ công của địa phương; (3) Môi trường sống và làm việc; (4) Nguồn nhân lực; và (5) Kênh cung cấp thông tin. Từ kết quả nghiên cứu, bài báo đề xuất một số hàm ý chính sách cho các nhà lãnh đạo tỉnh Đắk Nông tham khảo nhằm đẩy mạnh thu hút đầu tư cho tỉnh Đắk Nông.

Tì khóa: Marketing địa phương, thu hút đầu tư, Đắk Nông.

\begin{abstract}
Marketing place plays an important role in building a local image to attract investors, tourists, residents and laborers to the locality to promote local socio-economic development. This study conducted a survey of 200 investors inside and outside Dak Nong province to identify and measure 5 factors of marketing place affecting investment attraction in the province, including: (1) Supportive infrastructure for enterprise; (2) Local policies and public services; (3) Living and working environment; (4) Human resources; and (5) Information channel. From the research results, the paper proposes some policy implications for Dak Nong leaders to refer to promoting investment attraction for Dak Nong province.
\end{abstract}

Key words: Marketing place, investment attraction, Dak Nong province.

\section{Giới thiệu}

Thu hút đầu tư là một trong những nhiệm vụ quan trọng đối với chính quyền các địa phương trong điều kiện các địa phương đang rất cần vốn để đầu tư phát triển, đặc biệt là phát triển hệ thống hạ tầng và các lĩnh vực mà địa phương có thế mạnh. Thực tế thời gian qua, có khá nhiều các địa phương đã có những thành công khá ngoạn mục trong việc thu hút đầu tư như Bình Dương, Đồng Nai, Vĩnh Phúc, Thái Nguyên... Có nhiều yếu tố dẫn đến thành công nhưng một trong những yếu tố được nhắc đến nhiều là các địa phương này đã biết vận dụng marketing địa phương vào hoạt động thu hút đầu tư.

\footnotetext{
${ }^{1}$ Trường Đại học Tài chính - Marketing
} 
Đắk Nông là một tỉnh còn non trẻ, mới thành lập trên 15 năm và thuộc phía nam Tây Nguyên. Với đặc điểm về vị trí địa lý, điều kiện tự nhiên và xã hội, Đắk Nông có khá nhiều lợi thế để phát triển.

Về nông nghiệp, Đắk Nông với đặc thù có đến $66 \%$ diện tích là đất bazan rất phù hợp để phát triển nông nghiệp, nhất là các loại cây công nghiệp, cây ăn quả có giá trị kinh tế cao. Trong đó, một số loại cây hiện nay có diện tích và sản lượng lớn như cà phê (hơn 120.000 ha), hồ tiêu (hơn 39.200 ha).

Về tiềm năng du lịch, trên địa bàn tỉnh có nhiều thắng cảnh thiên nhiên như các thác nước hùng vĩ nằm giữa rừng già như thác Trinh Nữ, thác Đray H’Linh, Đray Sáp, thác Diệu Thanh, thác Gấu, thác Chuông, thác Ngầm (trong lòng núi), thác Liêng Nung, Đắk GLung... Các khu bảo tồn thiên nhiên Nam Nung (25.000 ha), Tà Đùng (28.000 ha). Đặc biệt, các buôn làng đồng bào dân tộc ít người với những nét sinh hoạt văn hóa truyền thống độc đáo và đặc sắc. Ngoài ra, Đắk Nông còn có công viên địa chất trải dài trên $2.000 \mathrm{~km} 2$ với hệ thống hang động núi lửa phân bố khu vực dọc sông Krông Nô được phát hiện từ năm 2007. Hệ thống hang động núi lửa Krông Nô ẩn chứa nhiều bí ẩn về sự thành tạo, các tổ hợp khoáng vật, đa dạng sinh học và di chỉ khảo cổ vô cùng qúy giá. Công viên địa chất này đang được tỉnh Đắk Nông trình UNESCO công nhận là công viên Địa chất toàn cầu. Đây được xem là một tiềm năng phát triển rất lớn về khoa học và du lịch.

Về công nghiệp khai thác và chế biến, Đắk Nông là tỉnh rất giàu tiềm năng về tài nguyên khoáng sản, trong đó đặc biệt là quặng bô-xít. Các khoáng sản quý hiếm khác cũng rất đa dạng, như vàng, đá quí ngọc bích, saphia trắng; volfram, thiếc, antimony và nguyên liệu sản xuất vật liệu xây dựng như đất sét, cao lanh, puzơlan...

Tuy nhiên, theo đánh giá của UBND tỉnh Đắk Nông, tình hình thu hút đầu tư trong và ngoài nước trên địa bàn tỉnh trong thời gian qua vẫn còn nhiều hạn chế, các hoạt động kinh tế đối ngoại còn yếu, thu hút vốn đầu tư FDI chưa đáng kể và quy mô nhỏ bé, cả tỉnh mới chỉ thu hút được có vài dự án vốn FDI. Riêng năm 2017, không có dự án FDI đầu tư vào tỉnh Đắk Nông.

Vì vậy, để có thể đạt mục tiêu huy động vốn để đầu tư phát triển như mục tiêu của tỉnh đã đề ra, có rất nhiều việc tỉnh Đắk Nông cần phải làm, trong đó, vấn đề nghiên cứu, vận dụng các yếu tố marketing địa phương để xây dựng hình ảnh địa phương và thu hút đầu tư trong và ngoài nước mang tính cấp bách. Mục tiêu của bài viết trình bày cơ sở lý thuyết và mô hình nghiên cứu về các yếu tố marketing địa phương thu hút đầu tư và kết quả nghiên cứu thực tế tại tỉnh Đắk Nông, từ đó đề xuất một số kiến nghị đối với tỉnh Đắk Nông nhằm đẩy mạnh thu hút vốn đầu tư nhất là đầu tư FDI vào tỉnh này.

\section{Cơ sở lý thuyết và mô hình nghiên cứu}

\subsection{Khái niệm và các lýthuyết về marketing} dịa phưo'ng

Vai trò của marketing đối với việc phát triển kinh tế của các quốc gia đã được các nhà kinh tế đề cập đến từ nhiều thập niên qua (Drucker 1958; Reddy \& Campbell 1994, Kotler \& ctg 2013, Berkowitz \& ctg 1994). Nhiều quốc gia tuy không có nguồn tài nguyên và nhân lực dồi dào nhưng nhờ có chiến lược và chương trình marketing địa phương hiệu quả và đã biến địa phương của mình thành những nơi phát triển bền vững (Hồ Đức Hùng, 2004). 
Marketing địa phương (Marketing Places) được định nghĩa là "việc thiết lập hình ảnh về một địa phương để thỏa mãn nhu cầu của những thị trường mục tiêu" (Kotler \& ctg, 2010), trong đó, thị trường mục tiêu của marketing địa phương chính là những khách hàng mà các chủ thể làm marketing địa phương hướng đến, bao gồm du khách tham quan du lịch, cư dân và người lao động, các nhà đầu tư hiện có và nhà đầu tư từ nơi khác, thị trường xuất khẩu.

Về vĩ mô, các nhà marketing tập trung vào vai trò của marketing phát triển kinh tế của một quốc gia, một địa phương (Reddy \& Campbell 1994). Tuy nhiên, khi đề cập đến marketing thì thương hiệu địa phương là đơn vị cơ bản để marketing hướng tới. Như vậy, về mặt marketing, chúng ta có thể xem một địa phương hay một quốc gia như một doanh nghiệp, có thương hiệu, gọi là "thương hiệu địa phương" để phân biệt với thương hiệu sản phẩm/dịch vụ của các đơn vị kinh doanh. Với quan điểm này, xét về nguyên lý marketing thì marketing một thương hiệu địa phương và marketing thương hiệu sản phẩm không khác nhau nhiều (Reddy \& Campbell 1994).

Marketing địa phương khác biệt với marketing sản phẩm đó là nhà marketing. Đối với thương hiệu là sản phẩm, nhà marketing là bộ phận marketing của doanh nghiệp, còn nhà marketing địa phương thì bao gồm nhiều thành phần khác nhau như chính quyền địa phương, cộng đồng kinh doanh và cộng đồng dân cư (Kotler và ctg, 2010)

Cũng theo Kotler \& ctg (2010), marketing địa phương không chỉ hiểu là hành động truyền thông quảng bá cho địa phương đó, mà marketing địa phương còn hướng tới việc tạo lập một địa phương nhằm thỏa mãn nhu cầu của thị trường mục tiêu. Các nhà làm marketing địa phương phải tạo ra được những "sản phẩm" địa phương hấp dẫn, thỏa mãn được nhu cầu của khách hàng đang mong đợi. Một địa phương không chỉ là một không gian địa lý, một thị trường với một cộng đồng dân cư nhất định mà còn bao gồm các yếu tố vô hình như văn hóa, xã hội, lịch sử, dân tộc.

Từ đó có thể hiểu, “marketing địa phương là những hoạt động của giới chức chính quyền và cộng đồng dân cư nhằm xây dựng và phát triển một hệ thống các giá trị của một địa phương, đồng thời truyền thông quảng bá các giá trị đó tới các nhà đầu tư, các nhà kinh doanh, các đối tượng khách du lịch, và nguồn lao động chất lượng cao nhằm thu hút họ tới địa phương để thúc đẩy sự phát triển địa phương”.

Trong lý thuyết marketing hiện đại, marketing địa phương là một trong những chính sách không thể thiếu trong quá trình quản lý. Xét về mặt "vi mô", marketing có thể xem xét ở phạm vi một sản phẩm nào đó của doanh nghiệp; xét về mặt "vĩ mô", marketing tập trung vào việc phát triển kinh tế của một quốc gia, tỉnh/ thành phố gồm marketing nhà đầu tư, khách du lịch, các chuyên gia, nhân vật nổi tiếng vào địa phương (Reddy và Campbell, 1994). Như vậy, có thể xem thương hiệu một quốc gia hay tỉnh/ thành phố là một "thương hiệu địa phương". Để thành công trong quá trình kinh doanh, các doanh nghiệp phải marketing cho sản phẩm của doanh nghiệp thì "nhà marketing địa phương" cần phải marketing cho quốc gia hay tỉnh/ thành phố (Kotler và ctg, 2013). Marketing địa phương thực chất là một sự phối hợp các nguồn lực của địa phương nhằm thỏa mãn nhu cầu khách hàng mục tiêu của địa phương (nhà đầu tư, kinh doanh, chuyên gia, du khách...) và để đạt được mục tiêu của địa phương là phát triển cũng như gia tăng chất lượng cuộc sống cho 
mọi thành viên trong địa phương (Nguyễn Đình Thọ và Nguyễn Thị Mai Trang, 2009).

\subsection{Marketing địa phưong và vấn đề thu hút đầu tư}

Trong thời đại ngày nay, các địa phương sẽ không thể tự phát triển được nếu không có các nguồn lực từ bên ngoài địa phương. Trong các nguồn lực để phát triển thì vốn đầu tư là một yếu tố vô cùng quan trọng.

Tuy nhiên, vấn đề là làm thế nào để các nhà đầu tư quan tâm đầu tư vốn vào một địa phương? Trong bối cảnh địa phương (tỉnh, thành, quốc gia) nào cũng muốn thu hút các nhà đầu tư về với địa phương mình, trong khi số lượng các nhà đầu tư có tiềm năng luôn luôn có giới hạn thì đương nhiên các nhà đầu tư sẽ có nhiều lựa chọn để xem xét nên đầu tư vào địa phương nào. Các nhà đầu tư thường chỉ đầu tư vào địa phương nào đáp ứng tốt nhất yêu cầu và kỳ vọng của họ. Các yếu tố nhà đầu tư quan tâm hàng đầu khi quyết định địa phương để đầu tư là nguồn nhân lực chất lượng cao và giá rẻ, nguồn nguyên liệu dồi dào, hạ tầng kinh tế - xã hội phát triển và một yếu tố vô cùng quan trọng khác là môi trường đầu tư. Chính môi trường đầu tư là yếu tố ảnh hưởng đến chi phí đầu tư (kể cả chi phí chính thức và phi chính thức) của nhà đầu tư. Việc vận dụng marketing địa phương vào lĩnh vực thu hút đầu tư chính là các hoạt động của chính quyền các địa phương trong việc nghiên cứu, tìm hiểu nhu cầu của nhà đầu tư và làm thỏa mãn nhu cầu của họ khi đầu tư vào địa phương (Quelch. 2005).

Theo quan điểm của Ashworth \& Voogd (1990), marketing địa phương nhằm thu hút đầu tư là quá trình, trong đó, địa phương tổ chức thực hiện các hoạt động hướng đến việc đáp ứng nhu cầu của khách hàng (nhà đầu tư) mục tiêu trên cơ sở đảm bảo lợi ích xã hội và hiệu quả kinh tế, phù hợp với mục tiêu đã đề ra. Quan điểm này cho thấy, marketing địa phương là một quá trình được thực hiện bởi các địa phương nhằm đáp ứng nhu cầu của khách hàng mục tiêu, trên góc độ thu hút đầu tư thì khách hàng ở đây là các nhà đầu tư tiềm năng.

Nghiên cứu những chiến lược marketing địa phương thành công của Seppo K.Nairisto (2003) đã chỉ ra nhóm các nhân tố có tầm quan trọng quyết định sự thành công của một địa phương gồm chín nhân tố, trong đó bao gồm năm nhân tố thuộc nội bộ địa phương (nhóm hoạch định, tầm nhìn và phân tích chiến lược, bản sắc và hình ảnh địa phương, mô hình hợp tác công - tư, lãnh đạo địa phương) và bốn nhân tố vĩ mô bên ngoài (đoàn kết chính trị, thị trường toàn cầu, phát triển địa phương, và sự trùng khớp quy trình).

Địa phương khi lựa chọn ngành nghề hay nhà đầu tư cần thu hút sẽ phụ thuộc vào: (1) mục tiêu và năng lực của địa phương; (2) khả năng "sinh lời” (hay đạt được mục tiêu) cho địa phương từ nhà đầu tư hay ngành nghề khuyến khích đầu tư; và (3) cường độ cạnh tranh trên thị trường thu hút đầu tư. Việc xác định và lựa chọn khách hàng mục tiêu cho phép các chủ thể marketing huy động và sử dụng hiệu quả nguồn lực của mình nhằm đạt được các mục tiêu đã xác định. Đối với các địa phương, việc tạo ra giá trị gia tăng cho nhà đầu tư là một thách thức lớn. Quá trình này đặt ra yêu cầu về hệ thống hoàn chỉnh đối với sản phẩm lãnh thổ để tối ưu giá trị gia tăng địa phương có thể cung cấp cho khách hàng mục tiêu.

Trong khi đó, Nguyễn Huy Hoàng (2017) thì cho rằng, với nhiều biến đổi và thách thức trong môi trường kinh doanh toàn cầu, các địa phương cần thực hiện một kế hoạch marketing 
mang tính chiến lược nhằm thu hút đầu tư một cách có hiệu quả. Một địa phương có kế hoạch chiến lược marketing toàn diện và rõ ràng sẽ đảm bảo thu hút đầu tư với một tầm nhìn dài hạn, hướng vào các mục tiêu phát triển bền vững, tránh tình trạng vụn vặt, thiếu định hướng trong thu hút đầu tư. Các hoạt động marketing địa phương khi đó sẽ góp phần thu hút đầu tư theo đúng mục tiêu và định hướng phát triển của địa phương. Sơ đồ dưới đây thể hiện mối quan hệ giữa địa phương và các nhà đầu tư tiềm năng mà địa phương hướng tới.

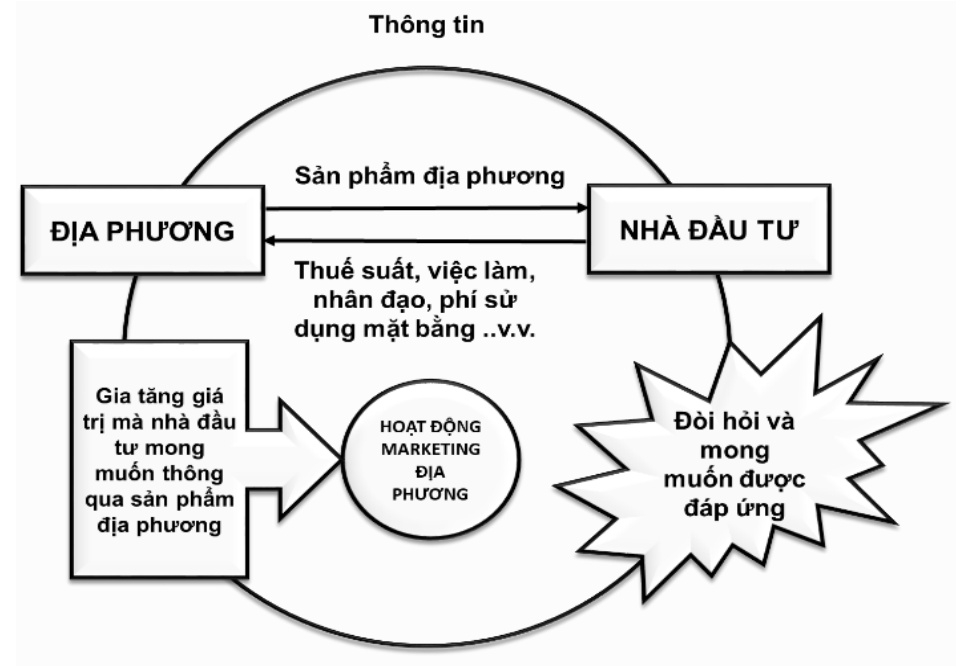

Hình 1. Mô hình mối quan hệ giữa địa phương và nhà đầu tư/doanh nghiệp Nguồn: Nguyễn Huy Hoàng (2017)

Chiến lược marketing địa phương với mục tiêu thu hút đầu tư có mối quan hệ chặt chẽ với nhau. Xây dựng chiến lược marketing địa phương nhằm mục đích thu hút đầu tư phải trả lời được ba câu hỏi chính: (i) vị thế hiện tại của địa phương trên thị trường đầu tư; (ii) vị trí mong muốn trong tương lai của địa phương trên thị trường đầu tư; (iii) giải pháp của địa phương nhằm mong muốn đạt được vị trí đó.

Ở một nghiên cứu khác, xuất phát từ bản chất của marketing, chiến lược marketing địa phương nhằm thu hút đầu tư thể hiện qua những hoạt động cụ thể bao gồm: Phân tích môi trường, dự báo tiềm năng, phân đoạn, lựa chọn và định vị thị trường mục tiêu và đặc biệt là chính sách marketing hỗn hợp. Tiếp cận marketing 4.0 của Kotler (2018), chiến lược marketing hỗn hợp
4C, khách hàng mục tiêu trong ngữ cảnh này được hiểu là các nhà đầu tư, các doanh nghiệp đã, đang và sẽ có ý định đầu tư vào địa phương, bao gồm: (1) Customer Solutions (Giải pháp cho nhà đầu tư); (2) Customer Cost (Chi phí mà nhà đầu tư phải bỏ ra cho hoạt động của họ tại địa phương); (3) Convenience (Sự thuận tiện dành cho nhà đầu tư) và (4) Communication (Cách thức tương tác với nhà đầu tư). Các biến số này cần phải được phối hợp một cách hiệu quả nhằm đạt mục tiêu phát triển của địa phương, đồng thời tạo lập một hình ảnh hấp dẫn với các nhà đầu tư.

\subsection{Mô hình nghiên cúu}

Nhằm mục đích khám phá mối quan hệ ảnh hưởng của các yếu tố marketing địa phương trong 
bối cảnh của Đắk Nông tới sự hấp dẫn đầu tư, trên cơ sở tham khảo một số mô hình nghiên cứu của các tác giả trước, nhóm nghiên cứu hướng nội dung phân tích vào năm vấn đề cơ bản được tham khảo từ các nghiên cứu trước (Nguyễn Huy
Hoàng 2017, Seppo K.Nairisto, 2003): (1) Cơ sở hạ tầng hỗ trợ doanh nghiệp; (2) Chế độ chính sách và dịch vụ công của địa phương; (3) Môi trường sống và làm việc; (4) Nguồn nhân lực và (5) Kênh cung cấp thông tin.

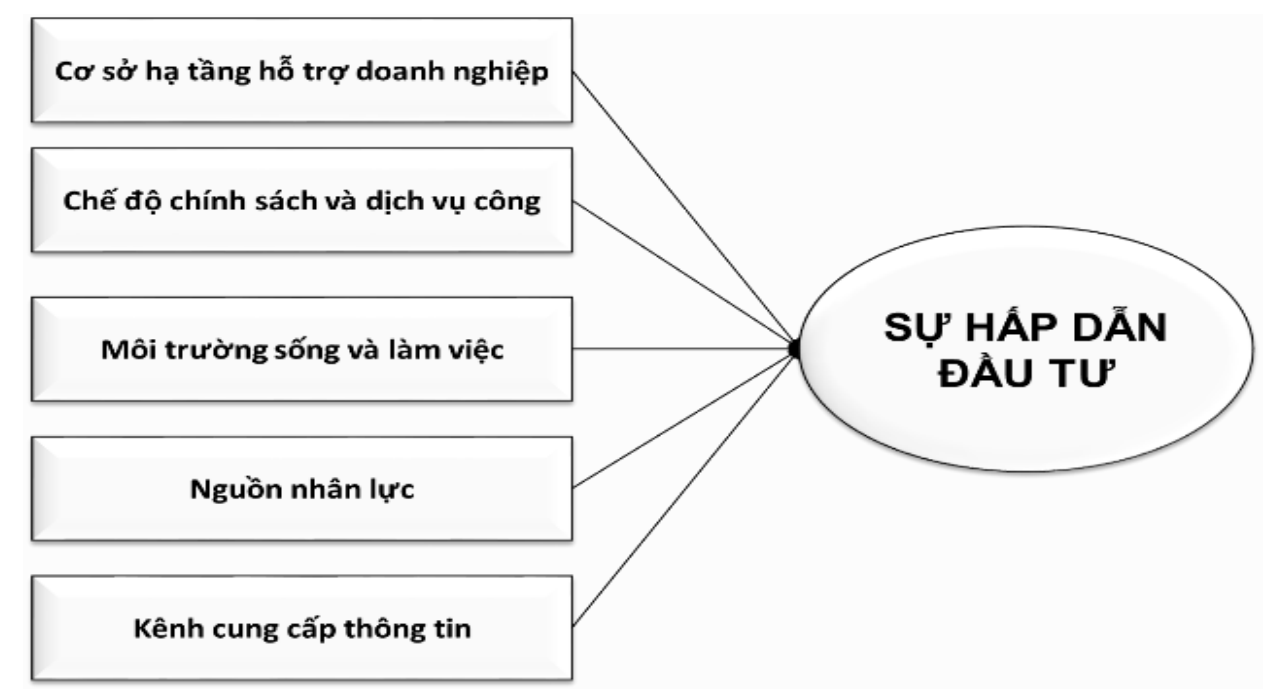

Hình 2. Mô hình nghiên cứu đề xuất

Nguồn: Nhóm tác giả xây dụng

Từ mô hình nghiên cứu đã trình bày, nhóm tác giả xác định một số giả thuyết nghiên cứu sau: (1) Giả thuyết H1: Cơ sở hạ tầng hỗ trợ doanh nghiệp có ảnh hưởng tích cực tới sự hấp dẫn doanh nghiệp đầu tư vào Tỉnh Đắk Nông. (2) Giả thuyết H2: Chế độ chính sách của địa phương có ảnh hưởng tích cực tới sự hấp dẫn doanh nghiệp đầu tư vào Tỉnh Đắk Nông. (3) Giả thuyết H3: Môi trường sống và làm việc có ảnh hưởng tích cực tới sự hấp dẫn doanh nghiệp đầu tư vào Tỉnh Đắk Nông. (4) Giả thuyết H4:
Nguồn nhân lực chất lượng cao có ảnh hưởng tích cực tới sự hấp dẫn doanh nghiệp đầu tư vào Tỉnh Đắk Nông. (5) Giả thuyết H5: Kênh cung cấp thông tin có ảnh hưởng tích cực tới sự hấp dẫn doanh nghiệp đầu tư vào Tỉnh Đắk Nông.

\section{Phương pháp nghiên cứu}

\subsection{Quy trình nghiên cứu}

Quy trình nghiên cứu được mô tả trong sơ đồ của hình 2 dưới đây: 


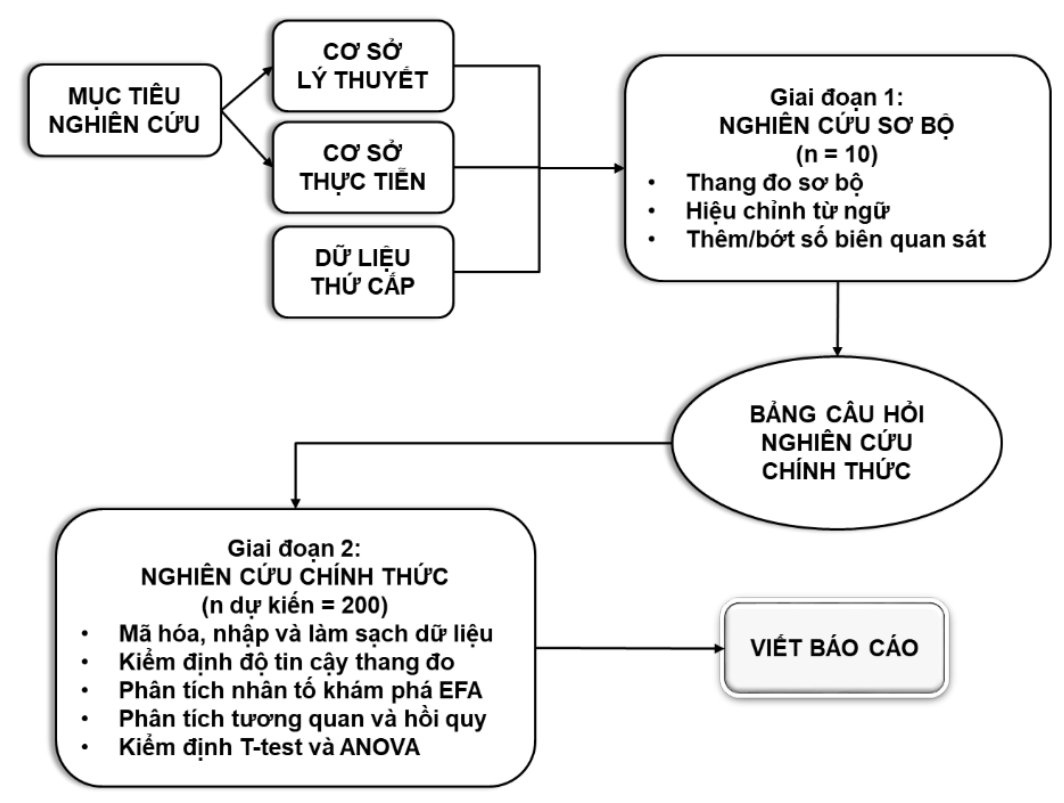

Hình 3. Quy trình thực hiện nghiên cứu

Nguồn: Nhóm tác giả xây dụng

\subsection{Phương pháp nghiên cúu}

Phương pháp nghiên cứu được sử dụng cho bài nghiên cứu này là phương pháp nghiên cứu định tính và nghiên cứu định lượng.

Nghiên cứu định tính được thực hiện thông qua phương pháp thảo luận nhóm. Một nhóm chuyên gia 10 người được mời đến để trao đổi theo dàn bài thảo luận. Thang đo ban đầu được tham khảo dựa vào thang đo của Nguyễn Huy Hoàng (2017), kết thúc thảo luận, nhóm nghiên cứu tổng hợp ý kiến, so sánh đối chiếu với các nghiên cứu trước để xây dựng bộ thang đo và bảng hỏi nháp (bảng hỏi được thiết kế theo thang đo Likert dạng cấu trúc). Thang đo được đo lường bằng các biến thành phần như sau: Một biến phụ thuộc ( $\left.\mathrm{Y}_{\mathrm{DT}}\right)$ thể hiện "Sự hấp dẫn đầu tư vào Đắk Nông” và năm biến độc lập với 39 biến quan sát, gồm: (1) Cơ sở hạ tầng hỗ trợ doanh nghiệp gọi là SI (bao gồm 14 biến quan sát từ $\mathrm{SI}_{1}$ đến $\mathrm{SI}_{14}$ ); (2) Chế độ chính sách và dịch vụ công của địa phương gọi là $\mathrm{PP}$ (bao gồm 7 biến quan sát từ $\mathrm{PP}_{1}$ đến $\mathrm{PP}_{7}$ ); (3) Môi trường sống và làm việc gọi là $\mathrm{EN}$ (bao gồm
6 biến quan sát từ $\mathrm{ENP}_{1}$ đến $\mathrm{ENP}_{7}$ ); (4) Nguồn nhân lực gọi là $H R$ (bao gồm 7 biến quan sát từ $\mathrm{HR}_{1}$ đến $\mathrm{HR}_{6}$ ); và (5) Kênh cung cấp thông tin gọi là $\mathrm{IC}$ (bao gồm 7 biến quan sát từ $\mathrm{IC}_{1}$ đến $\mathrm{IC}_{6}$ ). Sau khi hoàn thành việc xác lập các biến nghiên cứu, một Bảng câu hỏi nháp được hình thành gồm hai phần với hơn 50 câu hỏi cụ thể. Bước tiếp theo, nhóm nghiên cứu tiến hành phỏng vấn thử 30 đối tượng nhà đầu tư để đánh giá thang đo và chỉnh sửa bảng hỏi nháp thành bảng hỏi chính thức phục vụ nghiên cứu định lượng (chính thức).

Để thực hiện nghiên cứu chính thức, nhóm nghiên cứu tiến hành phỏng vấn trực tiếp 200 đối tượng nhà đầu tư trong nước và quốc tế (trong đó 120 nhà đầu tư đã đến đầu tư tại Đắk Nông, số còn lại là ở địa phương khác) bằng phương pháp lấy mẫu thuận tiện. Các bảng khảo sát thu thập được sau khi trải qua quá trình biên tập và nhập liệu được xử lý bằng phần mềm SPSS 20.0.

Những kỹ thuật được thực hiện trong phân tích dữ liệu định lượng bao gồm: phân tích nhân 
tố khám phá EFA; phân tích tương quan; phân tích hồi quy; phân tích phương sai (ANOVA) và thực hiện các kiểm định thống kê.

Nguồn dữ liệu thứ cấp cho nghiên cứu được tập hợp từ các báo cáo thống kê của Tổng cục Thống kê, Cục Thống kê tỉnh Đắk Nông, số liệu báo cáo của các Sở, Ban ngành tỉnh Đắk Nông và các công trình nghiên cứu có liên quan đã công bố.

\section{Kết quả nghiên cứu}

\subsection{Kết quả thống kê mô tả}

Với 200 bảng câu hỏi được phát ra đều thu lại thành công. Số liệu được mô tả chi tiết trong các bảng dữ liệu kết xuất dưới đây:

Bảng 1. Thống kê mô tả tỷ lệ mẫu khảo sát theo loại hình doanh nghiệp

\begin{tabular}{|c|l|c|c|}
\hline STT & \multicolumn{1}{|c|}{ Loại hình doanh nghiệp } & Số lượng & Tỷ lệ (\%) \\
\hline 1 & Doanh nghiệp tư nhân & 72 & 36,0 \\
\hline 2 & Công ty TNHH từ hai thành viên trở lên & 28 & 14,0 \\
\hline 3 & Công ty TNHH MTV & 58 & 29,0 \\
\hline 4 & Công ty cổ phần & 42 & 21,0 \\
\hline & Tổng cộng & 200 & 100 \\
\hline
\end{tabular}

Nguồn: Dũ liệu khảo sát của nhóm nghiên cưu

Bảng 2. Thống kê mô tả tỷ lệ mẫu khảo sát theo lĩnh vực hoạt động

\begin{tabular}{|c|l|c|c|}
\hline STT & \multicolumn{1}{|c|}{ Lĩnh vực hoạt động của doanh nghiệp } & Số lưọng & Tỷ lệ (\%) \\
\hline 1 & Công nghiệp/Sản xuất/ Xây dựng hạ tầng & 40 & 20,0 \\
\hline 2 & Dịch vụ/Thương mại & 114 & 62,0 \\
\hline 3 & Đào tạo/Tư vấn & 4 & 2,0 \\
\hline 4 & Nông nghiệp/Lâm nghiệp/Thủy sản & 8 & 4,0 \\
\hline 5 & Khai khoáng/Thủy điện & 14 & 7,0 \\
\hline 6 & Tài chính/Ngân hàng /Bảo hiểm & 10 & 5,0 \\
\hline & Tổng cộng & 200 & 100 \\
\hline
\end{tabular}

Nguồn: Dũ liệu khảo sát của nhóm nghiên cưu

\subsection{Kiểm định thang đo}

Kết quả kiểm định thang đo cho thấy tất cả các nhân tố trong thang đo đều đạt độ tin cậy với hệ số Cronbach Alpha > 0,6 và hệ số tương quan biến tổng đều lớn hơn 0,3 . Kết quả được thể hiện ở bảng sau: 


\section{Bảng 3. Kết quả kiểm định thang đo các biến độc lập}

\begin{tabular}{|c|l|c|c|}
\hline STT & Các yếu tố & Số biến quan sát & Hệ số Cronbach Alpha \\
\hline 1 & $\begin{array}{l}\text { Cơ sở hạ tầng hỗ trợ doanh nghiệp (Supporting } \\
\text { infrastructure) }\end{array}$ & 14 & 0,897 \\
\hline 2 & $\begin{array}{l}\text { Chế độ chính sách và dịch vụ công (Policy } \\
\text { and public service) }\end{array}$ & 7 & 0,872 \\
\hline 3 & Môi trường sống và làm việc (Environment) & 6 & 0,743 \\
\hline 4 & Nguồn nhân lực (Human Resources) & 6 & 0,795 \\
\hline 5 & $\begin{array}{l}\text { Kênh cung cấp thông tin cho nhà đầu tư } \\
\text { (Evaluates Information Channel) }\end{array}$ & 6 & 0,818 \\
\hline
\end{tabular}

Nguồn: Dũ liệu khảo sát của nhóm nghiên cưu

Đối với biến phụ thuộc với 7 biến quan sát hệ số Cronbach Alpha 0,856, vì vậy kết quả thang đo đạt yêu cầu để đưa vào phân tích tiếp theo.

\subsection{Kết quả phân tích nhân tố}

Kết quả xử lý số liệu, hệ số KMO = 0,793, hệ số Bartlett $=32,4,380$ và có ý nghĩa thống kê với độ tin cậy $95 \%$ đạt yêu cầu như bảng sau:

\section{Bảng 4. KMO and Bartlett's Test}

\begin{tabular}{|l|r|}
\hline Kaiser-Meyer-Olkin Measure of & 0,793 \\
Sampling Adequacy. & \\
Bartlett's Test Approx. Chi-Square & 324,380 \\
of Sphericity df & 21 \\
& Sig. \\
\hline
\end{tabular}

Nguồn: Phân tích dĩ liệu của nhóm nghiên cứu
Sau khi phân tích nhân tố khám phá EFA kỹ thuật PCA (Principal components Analysis) với phép xoay Varimax, tất cả các Hệ số tải nhân tố $($ Factor loading $)>0.5$; Hệ số eigenvalue $=1,974$ và phần trăm phương sai trích (Percentage of variance) $70,44 \%>50 \%$. Do đó, kết quả EFA đạt yêu cầu để đưa vào phân tích hồi quy.

\subsection{Kết quả Hồi quy}

Thang đo các biến độc lập bao gồm 39 biến quan sát, sau khi phân tích nhân tố khám phá (EFA), rút trích được 5 nhân tố để đưa vào phân tích hồi quy.

\section{Bảng 5. Kết quả phân tích hồi quy thu hút đầu tư}

\begin{tabular}{|l|c|c|c|c|c|}
\hline \multirow{2}{*}{ Các yếu tố } & \multicolumn{2}{|c|}{ Hệ số chưa chuẩn hóa } & Hệ số chuẩn hóa & \multirow{2}{*}{ Trị số $\mathrm{t}$} & $\begin{array}{c}\text { Mức ý nghĩa } \\
\text { (Sig) }\end{array}$ \\
\cline { 2 - 4 } & $\mathbf{B}$ & Sai số chuẩn & Beta & & 0,060 \\
\hline Hằng số & 0,004 & 0,071 & & 7,411 & 0,952 \\
\hline HR & 0,521 & 0,070 & 0,518 & 4,599 & 0,000 \\
\hline SI & 0,323 & 0,071 & 0,322 & 5,211 & 0,000 \\
\hline EN & 0,366 & 0,070 & 0,365 & 2,197 & 0,031 \\
\hline PP & 0,154 & 0,070 & 0,154 & 1,806 & 0,074 \\
\hline IC & 0,127 & 0,072 & 0,126 & & \\
\hline
\end{tabular}

Nguồn: Phân tích dũ liệu của nhóm nghiên cưu 
Kết quả kiểm định mô hình nghiên cứu bằng hồi quy tuyến tính bội giữa các yếu tố sự hấp dẫn đầu tư cho thấy cả 5 yếu tố tác động dương với các yếu tố của thực trạng thu hút đầu tư ở mức ý nghĩa $\mathrm{p}<0.05$. Hệ số phóng đại phương sai VIF đều nhỏ hơn 10 nên không có hiện tượng đa cộng tuyến. Giá trị F ở mức ý nghĩa thống kê Sig. $=.000$, cho thấy mô hình hồi quy xây dựng được là phù hợp với bộ dữ liệu thu thập được. Hệ số $\mathrm{R}^{2}$ điều chỉnh cho thấy độ tương thích của mô hình là 70,4\% hay nói cách khác khoảng $70,4 \%$ sự biến thiên của biến phụ thuộc thực trạng thu hút đầu tư được giải thích bởi 5 yếu tố.

Mối quan hệ nhân quả giữa các yếu tố thu hút đầu tư đối với thực trạng thu hút đầu tư dựa trên kết quả phân tích hồi quy bội của nghiên cứu được thể hiện bằng phương trình hồi quy chuẩn hóa như sau:

$$
\begin{aligned}
\mathrm{Y}_{\mathrm{DT}}= & 0,518 \mathrm{HR}+0,322 \mathrm{SI}+0,365 \mathrm{EN} \\
& +0,154 \mathrm{PP}+0,126 \mathrm{IC}
\end{aligned}
$$

Tức là: Sự thu hút đầu tư vào Tỉnh Đắk Nông $=0,518$ (Nguồn nhân lực) $+0,322(\mathrm{Co}$ sở hạ tầng) $+0,365$ (Môi trường sống và làm việc) $+0,154$ (Chế độ chính sách và dịch vụ công) $+0,126$ (Kênh cung cấp thông tin)

Kết quả nghiên cứu đã chỉ ra sự tác động của yếu tố nguồn nhân lực lớn nhất với hệ số Beta = 0,518 ; kế đến yếu tố cơ sở hạ tầng $(0,322)$, môi trường sống và làm việc $(0,365)$; chế độ chính sách và dịch vụ công $(0,154)$ và cuối cùng kênh cung cấp thông tin $(0,126)$.

Xét về thực tiễn, so sánh với các kết quả nghiên cứu ở một số địa phương khác và thông qua thảo luận nhóm chuyên gia thì kết quả nghiên cứu này đã phản ánh đúng thực tiễn tỉnh Đắk Nông trong thu hút đầu tư.

\section{Kết luận và hàm ý chính sách}

\subsection{Kết luận}

Bài nghiên cứu đã sử dụng giả thuyết mô hình các yếu tố marketing địa phương tác động đến thu hút đầu tư tại tỉnh Đắk Nông gồm 5 nhóm yếu tố gồm: (1) Cơ sở hạ tầng hỗ trợ doanh nghiệp (SI); (2) Chế độ chính sách và dịch vụ công của địa phương (PP); (3) Môi trường sống và làm việc (EN); (4) Nguồn nhân lực (HR); và (5) Kênh cung cấp thông tin cho nhà đầu tư (IC). Kết quả nghiên cứu khảo sát và xử lý dữ liệu cho thấy cả 5 nhóm yếu tố nói trên đều có ảnh hướng trực tiếp đến thu hút đầu tư tại tỉnh Đắk Nông với mức ý nghĩa $\mathrm{p}<0,05$. Trong đó nhóm yếu tố "Nguồn nhân lực - HR" ảnh hưởng mạnh nhất với trọng số tác động là 0,518 , kế đến là nhóm yếu tố "Môi trường sống và làm việc- EN" với trọng số 0,365 , tiếp đến là nhóm yếu tố "Cơ sở hạ tầng-SI" với trọng số 0,322, tiếp đến là nhóm yếu tố "Chế độ chính sách thu hút đầu tư của tỉnh - PP" với trọng số 0,154 và cuối cùng là nhóm yếu tố "Kênh thông tin cho nhà đầu tư - IC" với trọng số là 0,126 . Kiểm định thống kê cho thấy không xảy ra hiện tượng đa cộng tuyến và các nhân tố độc lập giải thích được 70,4\% ý nghĩa của mô hình.

\subsection{Một số hàm ý chính sách}

Để thu hút các nhà đầu tư vào tỉnh Đắk Nông, trên cơ sở kết quả nghiên cứu, bài báo đề xuất một số hàm ý chính sách như sau:

Thứ nhất là Nguồn nhân lục (Human Resources)

Tận dụng được nguồn nhân lực giá rẻ chính là một trong những lý do mà các nhà đầu tư đến với Việt Nam nói chung và Đắk Nông nói 
riêng. Nguồn lao động giá rẻ dồi dào chính là một trong những lý do mà các nhà đầu tư đến với Việt Nam, nhưng đó cũng không phải là điểm mạnh của Đắk Nông. Nhà đầu tư đánh giá tốt năng suất lao động $(3,68)$, tuy nhiên, khan hiếm lao động bậc cao hoặc người quản lý đáp ứng nhu cầu của doanh nghiệp $(2,84)$.

Nguồn nhân lực luôn giữ vai trò quan trọng nhất trong mọi chiến lược phát triển. Tỉnh Đắk Nông cần có chính sách tốt để đào tạo, phát triển, thu hút được nhiều nhân lực chất lượng cao cho địa phương.

\section{Thứ hai là Môi trường sống và làm việc (Environment)}

Môi trường sống và làm việc là yếu tố thứ hai được các nhà đầu tư quan tâm khi đầu tư vào Đắk Nông. Khi đầu tư vào một địa phương, các nhà đầu tư (thậm chí kể cả gia đình họ) sẽ phải thường xuyên sống và làm việc lâu dài tại địa phương đó, vì vậy yếu tố này nhà đầu tư rất quan tâm. Thực tế ở Đắk Nông có quá ít điểm văn hóa, vui chơi, chưa đáp ứng được nhu cầu sinh sống và làm việc tại địa phương. Ngược lại, người dân thân thiện được các nhà đầu tư đánh giá tốt. Cộng đồng dân cư có vai trò rất quan trọng trong việc củng cố và khuếch trương hình ảnh của địa phương. Thái độ và hành vi của cư dân địa phương sẽ có tác động tiêu cực hay tích cực, trực tiếp hay gián tiếp không chỉ đối với việc thu hút nhà đầu tư của địa phương mà còn ảnh hưởng mạnh mẽ đến mức độ trung thành của họ đối với địa phương.

Rất cần có kế hoạch chiến lược truyền thông để người dân thấy được vị trí của mình trong một chiến lược tổng thể marketing địa phương nhằm phát triển kinh tế xã hội một cách bền vững hơn.
Thứ ba là Cơ sở ha tầng hỗ trọ doanh nghiệp (Supporting Infrastructure)

Cơ sở hạ tầng hỗ trợ doanh nghiệp là nhóm yếu tố thứ ba mà các nhà đầu tư quan tâm. Đối với Đắk Nông, trong các yếu tố cấu thành cơ sở hạ tầng hỗ trợ doanh nghiệp, thì hai yếu tố thuộc về chi phí là giá điện $(2,94)$ và giá nước $(3,01)$ bị nhà đầu tư đánh giá thấp. Bên cạnh đó các hệ thống ngân hàng $(3,78)$ và hệ thống thông tin $(3,97)$, hệ thống cấp điện $(3,83)$ được đánh giá cao nhất. Tổng quan nhìn lại, hai yếu tố bị đánh giá thấp thì phạm vi Tỉnh không quyết định được mà phụ thuộc vào chính sách giá phí của Trung ương quy định, còn các yếu tố được đánh giá cao lại chính là sự chủ động thiết lập hạ tầng của địa phương. Điều này chứng minh sự nỗ lực của Tỉnh Đắk Nông trong những hoạt động quản lý mà Tỉnh có thể chủ động thực hiện. Tỉnh cần tiếp tục cố gắng theo chiều hướng tốt như hiện nay, đồng thời kiến nghị với Chính phủ hỗ trợ giá điện, nước cho các doanh nghiệp trong từng giai đoạn đầu tư đối với các địa phương thuộc vùng núi như Đắk Nông.

Thứ tư là Chế độ chính sách và dịch vụ công (Policy and Public service)

Ảnh hưởng từ chính quyền địa phương (trọng số 3,56) và Sự hỗ trợ của các cơ quan an ninh (trọng số 3,60) được đánh giá cao nhất. Điều này khẳng định những cố gắng to lớn của Đắk Nông trong những năm vừa qua. Ngược lại, Chính sách ưu đãi đầu tư (trọng số 3,18) và Dịch vụ hành chính pháp lý (trọng số 3,26 ) được các nhà đầu tư đánh giá thấp hơn. Tỉnh Đắk Nông cần lưu ý cải cách các vấn đề này để nâng cao chỉ số năng lực cạnh tranh cấp tỉnh (PCI), đồng thời làm tăng sự hài lòng của các Nhà đầu tư với địa phương. 
Thứ năm là Kênh cung cấp thông tin cho nhà đầu tư (Information Channel)

Đa số các nhà đầu tư tìm kiếm thông tin từ nhiều nguồn khác nhau, trang Web của Tỉnh là nơi có nhiều nhà đầu tư tham khảo (trọng số $3,62)$. Tiếp theo là Nguồn thông tin từ Bộ $\mathrm{KH}$ \& ĐT (trọng số 3,55 ) và Phòng Thương mại và Công nghiệp Việt Nam (VCCI) với trọng số 3,43 .
Tuy nhiên, điều quan trọng chính là chất lượng của thông tin cung cấp. Trang web của tỉnh được nhiều nhà đầu tư tham khảo nhưng họ lại đánh giá chất lượng thông tin không cao so với các nguồn khác. Kết quả khảo sát cho thấy, các nhà đầu tư rất tin tưởng vào thông tin mà đối tác của họ cung cấp. Bên cạnh đó, thông tin có được từ các hội chợ, triển lãm hoặc từ các công ty nghiên cứu thị trường lại được các nhà đầu tư đánh giá cao hơn.

\section{TÀI LIỆU THAM KHẢO}

\section{Tiếng Việt}

Hồ Đức Hùng, 2012. Marketing địa phương với việc quảng bá thương hiệu TP Hồ Chí Minh. Tạp chí Kinh tế và phát triển số 36.

Kotler, P. \& ctg, 2013. Quản trị marketing, NXB Lao động xã hội.

Nguyễn Đình Thọ và Nguyễn Thị Mai Trang, 2009. Phuoong pháp nghiên cúu khoa học trong Quản trị kinh doanh. NXB Thống kê. Tp.HCM.

Nguyễn Huy Hoàng, 2017. Chiến lược marketing dịa phương: Mô hình và thang đo nghiên cúu, Tạp chí Công thương.

Quelch J., 2005, Tiếp thị địa phưong và quốc gia theo cách nào? Vietnamnet.

Tổng Cục Thống kê, 2016, 2017, 2018. Niên giám thống kê các năm 2016. 2017, 2018. NXB Thống $K \hat{e}$.

UBND tỉnh Đắk Nông, 2018. Quy hoạch Philip thể phát triển kinh tế xã hội tỉnh Đắk Nông đến 2035, tầm nhìn 2050. Báo cáo quy hoạch Tỉnh Đắk Nông.

\section{Tiếng Anh}

Ashworth, G.J. \& H. Voogd, 1990. Selling the City: Marketing Approaches in Public Sector Urban Planning. London: Belhaven Press

Berkowitz \& ctg, 1994. Marketing, 4 the dition. Von Hoffmann Press, USA.

Drucker, P. F., 1958. Marketing and Economic Development. Sage Jourrnals Volume: 22 issue: 3 , page(s): 252-259, Issue published: January 1, 1958

Harvey \& Jim Taylor, 2003. Local economic and policy. Blackwell Publication.

Kotler, P., \& ctg, 2002. Marketing Asian Places, Attracting investment, industry, and tourism to cities, states, and nations. John Wiley \& Sons (Asia).

Kotler, P., \& ctg, 2010. Marketing places. Free press, USA.

Kotler, P., 2018. Marketing 4.0: Moving from Traditional to Digital. Wiley published 
Reddy, A. C. \& D. P. Campbell, 1994. Marketing's Role in Economic Development. Westport: Quorum Books.

Seppo K. Nairisto, 2003. Success factors of place marketing: A study of place marketing in practices Northern Europe and The United States. Helsinki University of Technology. 